\title{
Petrol Fiyatlarının Firma Karlılı̆̆ı Üzerine Etkisi: BIST Kimya, Petrol, Plastik Endeksi Firmaları Üzerine Bir Uygulama*
}

\author{
Ahmet Oğuz AKGÜNEŞ**
}

\section{ÖZET}

Bu çalışmanin amacı petrol fiyatları ve BIST Kimya, Petrol, Plastik endeksinde bulunan firmaların karlılıkları arasındaki ilişkiyi araştırmaktır. Çalışmada endekste bulunan 18 firmanın 2009-2019 arasındaki çeyrek dönemlik verileri kullanılmıştır. Seriler arasındaki uzun dönemli ilişki Tam Düzeltilmiş En küçük Kareler (FMOLS) ve Dinamik En Küçük Kareler (DOLS) yöntemleri kullanılarak tahmin edilmiştir. Araştırmada ROA, ROE, ROS değişkenleri bağımlı değişkenler olarak +alınmış petrol, cari oran, likidite oranı ve kaldıraç oranı bağımsız değişkenler olarak alınmıştır. Araştırma sonuçlarına göre petrol fiyatlarındaki artış firma karlılı̆̆ını ayn yönde etkilemekte olup kaldıraç oranlarındaki artış ise firma karlılığını ters yönlü etkilemektedir.

Anahtar Kelimeler: Firma Karlılı̆̆, FMOLS-DOLS, Petrol Fiyatları, BIST Kimya Petrol Plastik Endeksi

JEL Sinıflandırması: C23, L20, G30.

\section{Effect of Oil Prices on Firm Profitability: Evidence from BIST Chemical, Petrol,} Plastic Index

\section{ABSTRACT}

The aim of the study is to investigate the effect of oil prices changes on firm profitability in BIST Chemical, Petrol, Plastic index companies using quarterly data in period from 2009 to 2019:Q3. The long-term relationship between the series has been estimated using Fully Modified Ordinary Least Squares (FMOLS) and Dynamic Ordinary Least Squares (DOLS) methods. ROA, ROE, ROS variables are used as dependent variables and the current ratio, liquid ratio, oil prices and leverage ratio are used as independent variables. According to the results, the increase in oil prices affects the profitability of the companies in the same direction however the increase in leverage ratios affects in the opposite direction.

Keywords: Firm Profitability, FMOLS-DOLS, Oil Prices, BIST Chemical- Petrol- Plastic Index Jel Classification: C23, L20, G30.

\footnotetext{
* Makale Gönderim Tarihi: 06.01.2020, Makale Kabul Tarihi: 16.03 .2020 , Makale Türü: Nicel Araştırma

** Dr. Öğr. Üyesi, Kırklareli Üniversitesi, Sosyal Bilimler Meslek Yüksekokulu, ahmetoguzakgunes@klu.edu.tr, Orcid ID: 0000-0003-3852-9332.
} 


\section{GíRiş}

Dünyada artan nüfus ve bireylerin gelirlerindeki artış enerji ihtiyacını arttırmıştır. Artan enerji ihtiyacı fosil yakıtlardan, yenilenebilir kaynaklardan, nükleer kaynaklardan, su kaynaklarından, doğalgazdan ve petrolden elde edilmektedir. Tüm bu enerji kaynaklarının yanında petrol, özellikle son yüzyıl içeresindeki kullanımı ile tüm ülkeler için en önemli enerji kaynaklarından birisi olmuştur. Ülkeler gelecek için petrol yerine yenilenebilir kaynakları tercih etmekle birlikte petrol ihtiyacını daha da azaltmaya yönelik politikalar izlemektedirler. Ancak petrol sadece enerji üretimi için değil tekstil, plastik, kimya vb. sektörlerde hammadde ihtiyacını gidermek içinde kullanılmaktadır. Bu bağlamda ayrı bir önem arz etmektedir.

Bu çalışma Türkiye'de faaliyet gösteren ve hisseleri Borsa İstanbul'da işlem gören kimya sektörü firmalarının karlılıklarının, petrol fiyatları ile ilişkisinin incelenmesi bakımından literatüre katkı sağlaması beklenmektedir.

Petrol fiyatlarında meydana gelen şoklar sadece ülkelerin enerji sorunu değil aynı zamanda firmaların üretim sorununun birer kaynağı olabilmektedir. Meydana gelen şoklar üretimi etkilemesi petrol ihraç veya ithal eden olmasına göre getirilerin artması veya azalması olarak ortaya çıkabilmektedir.

Petrol fiyatlarındaki değişimler ülkelerin ekonomilerini etkilemekle beraber bu ülkelerde faaliyet gösteren firmalar için önemli bir dış etken durumundadır. Bu bağlamda literatürde petrol fiyatlarında meydana gelen şoklar sonucunda finansal piyasalarda ve makroekonomik değişkenlerde meydana gelen değişimlere yönelik çeşitli çalışmalar bulunmaktadır (Barsky ve Kilian 2004:115, Hamilton 1996:215, Hammoudeh ve Li 2004:228, Hammoudeh vd. 2010:298). Petrol fiyatlarında meydana gelen şoklar sonucunda enflasyon, firma karlılıkları, firma piyasa değerleri etkilenmektedir. Firmaların karlılıkları ise aynı veya ters yönlü olarak sektöre göre farkl1lıklar gösterebilmektedir. Tüm bu etkilerin varlığına ve yönüne yönelik çeşitli çalışmalar yapılmıştır. Yapılan çalışmalarda petrol ve gaz üreten ülkelerde firmaların getirileri ile aynı yönlü, petrolün ana girdi olduğu piyasalarda ise ters yönlü bir ilişkinin olduğu ortaya konulmuştur (Chen vd. 1986:383, Huang vd. 1996:1, Kilian ve Park 2009:1267, Malik ve Ewing 2009:95, Nandha ve Faff 2008:986). Bu bağlamda petrolü ihraç eden ve ithal eden ülkelere göre petrolün etkisinin yönü değişebilmektedir.

Türkiye petrol ithal eden bir ülke olarak enerji ihtiyacının bir kısmını petrolden karşılamaktadır. Ayrıca petrol türevi ürünleri çeşitli mamullerin üretiminde birer hammadde olarak kullanmaktadır. Bu bağlamda hem enerji, üretimi hem de üretim girdisi olarak iki farklı ilişki söz konusudur. Bu bağlamda petrol fiyatları ve firmaların karlılıklarına yönelik çeşitli çalışmalar yapılmıştır (Kapusuzoğlu, 2011:99; İşcan, 2010:607).

Bu çalışmada Türkiye'de petrol türevi ürünleri enerji, hammadde olarak kullanabilen ve petrol türevi ürünleri satan kimya, petrol, plastik sektörü firmaları ele alınmış olup petrol fiyatlarındaki değişimin bu firmaların karlılıkları üzerine etkisi incelenmiştir. Çalışma sonucunda borsada işlem gören firmaların yöneticilerine yönelik çeşitli 


\section{LITERATÜR ÖZETI}

Petrol fiyatlarının getiri (Firma, Borsa) üzerine etkisine yönelik çeşitli çalışmalar yapılmıştır. Literatürde daha yoğun olarak petrol fiyatlarındaki değişimin firmaların hisse senedi getirileri üzerine etkisine yönelik çalışmalar bulunmaktadır. Bu çalışmalara nazaran daha sınırlı olmak kaydıyla firma karlılıklarına yönelik çalışmalar da bulunmaktadır. Bu bağlamda firma ve piyasa getirisine yönelik her iki literatür de dikkate alınmıştır.

Kriz zamanları dışında (Asya Krizi, ABD Finansal Krizi 2007-2008) petrol fiyatlarının ROE ile pozitif yönlü ve anlamlı bir ilişkinin olduğu ortaya konulmuştur (Dayanandan ve Donker, 2011:252). Bu kriz sürecinde ise petrol fiyatlarındaki değişimlerin borsalar ile ters yönlü bir ilişkisinin olduğunu ortaya koyan çalışmalar da bulunmaktadır (Filis vd. 2011:152).

Wattanatorn vd. (2012) petrol fiyatlarındaki artışın ABD ve Japonya'daki otomotiv endüstrisinin karlılığını olumsuz etkilediğini ortaya koymuşlardır. Çalışmalarında Tayland borsasında işlem gören firmaların 2001-2010 yılları arasındaki verilerle yapmış oldukları çalışmada petrol fiyatlarının enerji ve gıda sektörlerindeki firmaların ROA'ları ile anlamlı ve artı yönlü bir ilişkinin olduğunu ortaya koymuşlardır. Firma karlılığının yanı sıra petrol fiyatlarında meydana gelen değişimlerin borsa getirileri üzerine etkileri bulunmakta olup (Raza vd. 2016:290, Huang vd. 2015:493, Manimaran vd. 2009:2306) bu etki firma karlılığını da etkilemektedir.

Jones ve Kaul (1996), çalışmalarında Kanada, Japonya, Birleşik Krallık ve Birleşik Devletler'de ki borsa getirileri üzerine petrol fiyatlarının etkisini incelemişlerdir. Kanada ve Birleşik Devletler 'de petrol fiyatları ve borsa getirileri arasında ters yönlü ilişki olduğunu ortaya koymuşlardır. Bu sonuçlar ülke bazında olup global bir anlam taşımamaktadır. Sadorsky (2001), çalışmasında Kanada'da bulunan petrol ve gaz şirketlerinin karlılıkları ile petrol fiyatlarındaki değişimin arasında aynı yönlü bir ilişkinin olduğunu ortaya koymuştur. Benzer bir çalışma Al-Mudhaf ve Goodwin (1993) tarafından yapılmış olup çalışmalarında New York borsasında işlem gören 29 petrol firmasını ele almışlardır. Çalışma sonuçlarına göre petrol fiyatları ve firmaların getirileri arasında aynı yönlü bir ilişki olduğu ortaya konmuştur.

Arouri (2011) çalışmasında borsa ve sektör getirileri ile petrol fiyatları arasındaki ilişkiye yoğunlaşmıştır. Çalışması Avrupa pazarlarına yönelik olmuştur. Çalışmasının sonucunda petrol fiyatları ve hem gıda sektöründe faaliyet gösteren firmalar hem de petrol ve gaz firmaları arasında aynı yönlü bir ilişkinin varlığını ortaya koymuştur. Mohanty vd. (2013), petrol ve gaz fiyatlarındaki eksi yönlü değişimin petrol, gaz üreten ve dağıtan firmaların karlıklılarını daha fazla ve ters yönlü etkilediğini ortaya koymuşlardır.

Sharma ve Narayan (2014), NYSE'de listelenen 560 firmanın günlük verilerini kullanarak yapmış oldukları çalışmada petrol fiyatlarının firma getirilerinin varyansının karar vericisi olduğunu ortaya koymuşlardır. Ayrıca yatırımcıları petrol fiyatlarını tahmin ederek kazançlar elde edebileceklerini ortaya koymuşlardır.

Narayan ve Narayan (2014), çalışmalarında 1559 firmanın 1998-2009 yılları arasındaki verilerini kullanarak petrol fiyatlarındaki değişimlerin firma getirileri üzerine etkisini incelemişlerdir. Çalışmalarında firmaları yerel sermayeli ve yabancı sermayeli 
firmalar olarak ayırmış ve analiz sonuçlarını bu ayrıma göre raporlamışlardır. Çalışmalarında ayrıca petrol fiyatlarındaki psikolojik bariyerin etkisini incelemişlerdir. Çalışma sonuçlarına göre petrol fiyatları ve firma getirileri arasına anlamlı bir ilişki bulamamışlardır. Ancak petrol fiyatlarının 100 Dolar bariyerini aşması durumunda petrol fiyatları ve firma getirileri arasında anlamlı ve ters yönlü bir ilişki olduğunu ortaya koymuşlardır. Ayrıca bu ilişkinin yerel firmalarda, yabancı firmalara göre daha kuvvetli olduğunu raporlamışlardır.

Literatürde Türkiye üzerine yapılmış çeşitli çalı̧̧malar bulunmaktadır. Alper vd. (2016), çalışmalarında BIST İmalat sektöründe faaliyet gösteren firmaların 2000-2015 yılları arasındaki verilerini kullanmışlardır. Çalışma sonucunda petrol fiyatlarındaki değişimlerin firmaları karlıklıları ile anlamlı ve ters yönlü bir ilişkilerinin olduğunu ortaya konmuştur. Kapusuzoğlu (2011), çalışmasında BIST 30, BIST 50, BIST 100 endekslerinin petrol fiyatı için granger nedeni olduğu sonucuna ulaşmıştır. Ayrıca İşcan (2010), hisse senedi fiyatları ve petrol fiyatları arasında herhangi bir ilişkinin bulunmadığını raporlamıştır.

\section{VERI VE METODOLOJI}

Araştırmada BIST Kimya, Petrol, Plastik Endeksinde 2009-2019 yılları arasında verileri toplanabilen 18 firmanın verileri kullanılmıştır. Firmaların performansları için ROA, ROS, ROE, likidite oranı (asit test), cari oran ve finansal kaldıraç oranları kullanılmıştır. Firmaların 3-6-9-12 aylık verileri kullanılmış olup toplam 18 firmaya ait 774 gözlem yapılmıştır. Firma verileri Kamuyu Aydınlatma Platformundan (KAP) elde edilmiş olup sadece 2019 yılı için 3 çeyrek dönemlik veriler kullanılmıştır.

Çalışmada öncelikle serilerin durağanlıkları test edilmiş sonrasında aralarındaki uzun dönemli ilişkinin varlığı koentegrasyon testi ile analiz edilmiştir. Sonrasında uzun dönemli ilişkiye yönelik regresyon denklemleri Tam Düzeltilmiş En küçük Kareler (Fully Modified Ordinary Least Squres-FMOLS) ve Dinamik En Küçük Kareler (Dynamic Ordinary Least Squres-DOLS) yöntemleriyle kurularak tahmin edilmiştir. Çalışmada bağımsız değiş̧enlerin firma karlılığına olan etkisi analiz edilmiştir. Firma karlılığı ROA, ROE ve ROS değişkenleri ile ölçülmüş olup her bir değişken için ayrı bir hipotez kurulmuştur. Çalışmada kullanılan bağımlı ve bağımsız değişkenlere yönelik bilgiler Tablo 1'de gösterilmiştir.

Tablo 1. Değişkenler

\begin{tabular}{lll}
\hline Bağımlı Değişkenler & & \\
\hline ROA & Varlık Karlılı̆̆ı & Dönem Net Karı / Toplam Varlıklar \\
ROE & Öz sermaye Karlılığı & Dönem Net Karı / Öz kaynak \\
ROS & Säış Karlılığı & \\
\hline Bağımsıt Net Karı / Net Satışlar \\
\hline Petrol & & Çeyrek Dönem Ortalama Fiyat \\
Cari Oran & Brent Petrol Fiyatı & Dönen Varlıklar / KVYK \\
Likidite Oranı & Cari Oran & (Dönen Varlıklar - Stoklar) / KVYK \\
Kaldıraç & Likidite Oranı & Toplam Borç / Toplam Varlık \\
\hline \hline
\end{tabular}




\section{AMPIRIKK BULGULAR}

Araştırmada firma performansı hem karlılık hem de firmanın borçlarını ödeme gücü olarak ele alınmıştır. ROA, ROE ve ROS değişkenleri firmanın karlılık rakamlarını göstermekte olup cari oran, likidite oranı ve finansal kaldıraç firmanın borçlarını döndürme performansını ifade etmektedir. Araştırmada kullanılan bu değişkenlerin tanımlayıcı istatistikleri Tablo 2'de gösterilmiştir.

Tablo 2. Tanımlayıcı İstatistikler

\begin{tabular}{ccccc}
\hline Değişken & Ortalama & Standart Sapma & Min. & Max. \\
\hline Petrol & 78.28384 & 25.46487 & & 118.7106 \\
& & & 33.84270 & \\
ROA & 418.1021 & 589.1688 & -6670.000 & 3495.000 \\
ROE & 3639.354 & 13067.58 & -126917.0 & 83274.00 \\
ROS & -5379.539 & 55223.73 & -478020.0 & 95982.00 \\
Cari Oran & 18288.34 & 16745.86 & 2000.000 & 228142.0 \\
Likidite Oranı & 16162.94 & 16785.44 & -28148.00 & 227689.0 \\
Kaldıraç & 5151.508 & 2036.080 & 130.0000 & 18437.00 \\
\hline \hline
\end{tabular}

Araştırmada elde edilen veri seti 18 farklı firmaya ait olup bu verilerin firma karlılığına olan etkisi incelenmiştir. Değişkenler arası ilişsi panel veri yöntemi kullanarak ortaya konulmuştur. Bağımlı değişkenler ROA, ROE, ROS olup Cari Oran, Likidite Oranı ve Kaldıraç değişkenleri ise bağımsız değişkenlerdir.

Araştırma modeli oluşturmadan önce değişkenler arasında sahte ilişkilerin ortaya çıkmaması için değiş̧kenlerin durağan olması gerekmektedir. Değişkenlerin durağanlığını test etmek için 4 farklı birim kök testi uygulanmıştır. Bu testler Levin, Lin ve Chu testi, Im, Pesaran ve Shin W istatistiği Augmented Dickey- Füller (ADF) testi ve PP- Fisher Ki- kare testidir. Değişkenlerin düzey değerlerinde birim kök problemi olmasından dolayı 1. dereceden farkları alınarak tekrar test edilmişleridir. Test sonuçları Tablo 3’te gösterilmiştir. 
The Journal of Accounting and Finance- October/2020

(88): 225-236

Tablo 3. Birim Kök Testleri

\begin{tabular}{|c|c|c|c|c|c|c|c|c|c|}
\hline Test & Model & & ROA & ROE & ROS & Cari & Likidite & Kaldıraç & Petrol \\
\hline Levin, & Sabitli & $t$ & -26.732 & -24.087 & -21.367 & -18.984 & -22.268 & -21.748 & -11.817 \\
\hline Lin ve & & $\mathbf{p}$ & $0.00^{* *}$ & $0.00 * *$ & $0.00^{* *}$ & $0.00 * *$ & $0.00^{* *}$ & $0.00^{* *}$ & $0.00 * *$ \\
\hline \multirow[t]{3}{*}{ Chu } & Sabitli & t & -25.184 & -21.994 & -20.490 & -16.554 & -20.294 & -20.122 & -10.992 \\
\hline & ve & $\mathbf{p}$ & $0.00^{* *}$ & $0.00^{* *}$ & $0.00^{* *}$ & $0.00 * *$ & $0.00^{* *}$ & $0.00^{* *}$ & $0.00 * *$ \\
\hline & Trendli & & & & & & & & \\
\hline \multirow{3}{*}{$\begin{array}{c}\text { Breitung } \\
\text { t-ist. }\end{array}$} & Sabitli & t & -10.191 & -9.5705 & -7.6169 & -13.394 & -12.070 & -8.2744 & -10.114 \\
\hline & ve & $\mathbf{p}$ & $0.00 * *$ & $0.00 * *$ & $0.00^{* *}$ & $0.00 * *$ & $0.00^{* *}$ & $0.00 * *$ & $0.00 * *$ \\
\hline & Trendli & & & & & & & & \\
\hline \multirow{2}{*}{$\begin{array}{c}\text { Im, } \\
\text { Pes.ve }\end{array}$} & Sabitli & $\mathbf{t}$ & -27.169 & -26.056 & -23.586 & -23.697 & -23.999 & -22.714 & -10.466 \\
\hline & & $\mathbf{p}$ & $0.00^{* *}$ & $0.00^{* *}$ & $0.00^{* *}$ & $0.00 * *$ & $0.00^{* *}$ & $0.00^{* *}$ & $0.00^{* *}$ \\
\hline \multirow{3}{*}{$\begin{array}{l}\text { Shin W- } \\
\text { ist. }\end{array}$} & Sabitli & $\mathbf{t}$ & -26.187 & -24.896 & -22.425 & -22.330 & -22.380 & -21.391 & -8.0231 \\
\hline & ve & $\mathbf{p}$ & $0.00 * *$ & $0.00 * *$ & 0.00 & $0.00 * *$ & 0.00 & $0.00 * *$ & $0.00 * *$ \\
\hline & Trendli & & & & & & & & \\
\hline \multirow{5}{*}{$\begin{array}{c}\text { ADF - F. } \\
\text { Ki-kare }\end{array}$} & Sabitli & t & 513.460 & 514.680 & 407.989 & 457.028 & 471.008 & 444.960 & 177.553 \\
\hline & & $\mathbf{p}$ & $0.00^{* *}$ & $0.00^{* *}$ & $0.00 * *$ & $0.00 * *$ & $0.00 * *$ & $0.00^{* *}$ & $0.00 * *$ \\
\hline & Sabitli & $\mathbf{t}$ & 703.855 & 481.929 & 602.270 & 442.764 & 424.878 & 396.513 & 125.517 \\
\hline & ve & $\mathbf{p}$ & $0.00^{* *}$ & $0.00^{* *}$ & $0.00^{* *}$ & $0.00 * *$ & $0.00 * *$ & $0.00^{* *}$ & $0.00^{* *}$ \\
\hline & Trendli & & & & & & & & \\
\hline \multirow{5}{*}{$\begin{array}{c}\text { PP - F. } \\
\text { Ki-kare }\end{array}$} & Sabitli & $\mathbf{t}$ & 607.508 & 604.100 & 570.004 & 551.474 & 563.044 & 600.181 & 293.396 \\
\hline & & $\mathbf{p}$ & $0.00^{* *}$ & $0.00 * *$ & $0.00^{* *}$ & $0.00 * *$ & $0.00^{* *}$ & $0.00 * *$ & $0.00 * *$ \\
\hline & Sabitli & $\mathbf{t}$ & 3382.90 & 2634.88 & 2386.47 & 2550.08 & 3000.29 & 2910.54 & 233.723 \\
\hline & ve & $\mathbf{p}$ & $0.00^{* *}$ & $0.00^{* *}$ & $0.00^{* *}$ & $0.00 * *$ & $0.00 * *$ & $0.00^{* *}$ & $0.00^{* *}$ \\
\hline & Trendli & & & & & & & & \\
\hline
\end{tabular}

$\mathrm{H}_{0}$ :Birim kök vardır; $\mathrm{H}_{1}$ : Birim kök yoktur; *\%5 düzeyinde anlamlı; **\%1 düzeyinde anlamlı.

Tablo 3'te verilen test istatistiklerinin hesaplanan olasılık değerleri 0,05 değerinin altında olduğu için $\mathrm{H}_{0}$ hipotezi red edilmiş $\mathrm{H}_{1}$ hipotezi kabul edilmiştir. Bu bağlamda tüm değişkenlerin durağan olduğu, birim kök bulunmadığ 1 ortaya konulmuştur. Durağan oldukları ortaya konulan zaman serileri arasındaki uzun dönemli ilişkinin varlıği Pedroni eşbütünleşme testi ile araştırılmıştır. Pedroni testi her bir panel için ayrı ayrı uygulanmıştır. Pedroni (2000) eşbütünleşim testi panel zaman serilerinde kullanılmak üzere heterojen bir eşbütünleşme testi ortaya koymuştur. Test sonuçları Tablo 4'te gösterilmiştir. 
Tablo 4. Pedroni Eşbütünleşim Test Sonuçları

\begin{tabular}{lllllll}
\hline & \multicolumn{2}{c}{ Panel 1 } & \multicolumn{2}{c}{ Panel 2 } & \multicolumn{2}{c}{ Panel 3 } \\
\hline & İstatistik & Olasılık & İstatistik & Olasılık & İstatistik & Olasılık \\
\hline Panel v & -3.916203 & 1.000 & -0.879231 & 0.810 & -2.256104 & 0.988 \\
Panel v & -3.707592 & 0.999 & -3.240764 & 0.999 & -2.715353 & 0.996 \\
(Weighted) & & & & & & \\
Panel rho & -2.746574 & $0.003^{* *}$ & 0.659316 & 0.745 & -0.471455 & 0.318 \\
Panel rho & -2.466667 & $0.006^{* *}$ & -1.121953 & 0.130 & -1.677108 & $0.046^{*}$ \\
(Weighted) & & & & & & \\
Panel pp & -9.439111 & $0.000^{* *}$ & -2.021745 & $0.021^{*}$ & -2.020713 & $0.021^{*}$ \\
Panel pp & -9.419967 & $0.000^{* *}$ & -6.774549 & $0.000^{* *}$ & -6.584184 & $0.000^{* *}$ \\
(Weighted) & & & & & & \\
Panel ADF & -9.190156 & $0.000^{* *}$ & -4.361252 & $0.000^{* *}$ & 4.159424 & 1.000 \\
Panel ADF & -8.847450 & $0.000^{* *}$ & -7.521466 & $0.000^{*}$ & -3.554071 & $0.000^{* *}$ \\
(Weighted) & & & & & & \\
Grup rho & -0.169554 & 0.4327 & -0.021214 & 0.491 & -0.368628 & 0.356 \\
Grup pp & -10.35688 & $0.000^{* *}$ & -9.812181 & $0.000^{* *}$ & -5.666660 & $0.000^{* *}$ \\
Grup ADF & -7.536124 & $0.000^{* *}$ & -6.886145 & $0.000^{* *}$ & -2.629096 & $0.004^{* *}$ \\
\hline \hline
\end{tabular}

$\mathrm{H}_{0}$ : Seriler eşbütünleşik değildir; $\mathrm{H}_{1}$ : Seriler eşbütünleşiktir; *\%5 düzeyinde anlamlı; **\%1 düzeyinde anlamlı.

Analiz sonuçlarına göre her bir panel için elde edilen istatistik değerlerinin olasılıklarının ekseriyetinin $\% 5$ düzeyinin altında olmasından dolayı $\mathrm{H}_{0}$ reddedilmiş ve $\mathrm{H}_{1}$ kabul edilmiştir. Bu bağlamda panel zaman serilerinde uzun dönemli ilişkinin varlığı ortaya konulmuştur. Değişkenlerin birbirleri ile uzun dönemli ilişkileri bulunmaktadır. Söz konusu bu ilişkinin hangi değişkenler arasında olduğunu ve ilişkinin yönünü ortaya koyabilmek için Tam Düzeltilmiş En küçük Kareler (Fully Modified Ordinary Least Squres - FMOLS) ve Dinamik En Küçük Kareler (Dynamic Ordinary Least Squres) tahmincileri kullanılarak yapılmışlardır.

FMOLS yöntemi Christopoulos ve Tsionas (2004) tarafindan panel verinin tahmin edilebilmesi için ortaya konulmuş bir yöntemdir (Pradhan, 2016:57). FMOLS yöntemi eşbütünleşik denklemlerde uzun dönemden kaynaklanan korelasyonun neden olduğu problemlerden kurtulabilmek için bağımsız değişkenler ve hata terimi arasındaki içsellik ilişkisini, hata terimleri arasındaki otokorelasyonu dikkate almaktadır (Küçükaksoy vd. 2015:691). Bu bağlamda FMOLS yöntemi tutarlı ve sapmasız olup kurulan fonksiyonda içsellik ve otokorelasyondan kaynaklanan problemler düzeltilmektedir (Phillips ve Hansen, 1990:99).

DOLS yöntemi Stock ve Watson (1993) tarafindan bağımlı ve bağımsız değişkenler arasındaki uzun dönemli ilişkiyi araştırmak için geliştirilmiştir. DOLS yönteminde kurulan uzun dönem ilişki denkleminde dinamik unsurların dikkate alınıyor olması yöntemin kuvvetli 
taraflarından birisi olarak öne çıkmaktadır. FMOLS ve DOLS yöntemleri kullanılarak her bir panel için yapılan tahminlerin sonuçları Tablo 5'te gösterilmiştir.

Tablo 5. Panel 1 FMOLS - DOLS Tahmin Sonuçları

\begin{tabular}{lcccc}
\hline Panel 1 & \multicolumn{2}{c}{ FMOLS } & \multicolumn{2}{c}{ DOLS } \\
\hline Bağımsız & Uzun Dönemli & Olasılık Değeri & $\begin{array}{c}\text { Uzun Dönemli } \\
\text { Katsayı }\end{array}$ & Olasılık Değeri \\
Değişkenler & Katsayı & & 2.041419 & \\
\hline Petrol & 2.008671 & $0.000^{* * *}$ & $(2.062365)$ & $0.039^{* *}$ \\
& $(3.504231)$ & & -0.021944 & \\
Cari Oran & 0.026190 & 0.348 & $(-0.356713)$ & 0.721 \\
& $(0.937858)$ & & 0.077516 & \\
Likidite Oranı & 0.018768 & 0.494 & $(1.252123)$ & 0.211 \\
& $(0.683049)$ & & -0.015569 & \\
Kaldıraç & -0.044859 & $0.034^{* *}$ & $(-0.854248)$ & 0.393 \\
& $(-2.122601)$ & & & \\
\hline \hline
\end{tabular}

Panel 1; Bağımlı değişken ROA; *** \%1 Düzeyinde anlamlı; **\%5 Düzeyinde anlamlı; *\%10 Düzeyinde anlamlı.

Panel 1'de bağımlı değişken ROA olarak alınmış olup hem FMOLS hem de DOLS tahmincileri ile tahmin edilmiştir. Petrol değişkeni katsayıları 2.008671 (FMOLS) ve 2.041419 (DOLS) olarak gerçekleşmiş olup bu katsayıların olasılık değerleri 0.00 (FMOLS) ve 0.039 (DOLS) olarak gerçekleşmişlerdir. Hem FMOLS hem de DOLS yöntemine göre petrol değişkeni ROA'yı benzer katsayılarda açıklamaktadır. Petrol fiyatlarında meydana gelen 1 birimlik değişim ROA'yı 2.008671 (FMOLS) ve 2.041419 (DOLS) olarak etkilemektedir. Ancak kaldıraç oranında ilişki ters yönlü olarak gerçekleşmektedir (FMOLS: 0.044859). $\mathrm{Bu}$ bağlamda firmaların borçlarındaki artış ROA'yı azaltırken, petrol fiyatlarındaki artış ise ROA'yı arttırmaktadır. Panel 2'ye yönelik tahminler Tablo 6'da gösterilmiştir. 
Tablo 6. Panel 2 FMOLS - DOLS Tahmin Sonuçları

\begin{tabular}{lcccc}
\hline Panel 2 & \multicolumn{2}{c}{ FMOLS } & \multicolumn{2}{c}{ DOLS } \\
\hline Bağımsız & Uzun Dönemli & Olasılık Değeri & $\begin{array}{c}\text { Uzun Dönemli } \\
\text { Katsayı }\end{array}$ & Olasılık Değeri \\
Değişkenler & Katsayı & & 52.64233 & \\
\hline Petrol & 64.67786 & & $(1.642133)$ & 0.101 \\
& $(2.956504)$ & $0.003^{* *}$ & 0.344161 & \\
Cari Oran & 0.469407 & & $0.728124)$ & 0.466 \\
& $(1.609988)$ & 0.108 & 0.269166 & \\
Likidite Oranı & 0.008353 & & $0.471262)$ & 0.637 \\
& $(0.022594)$ & 0.982 & -0.592169 & \\
Kaldıraç & -0.546283 & & $(-1.324459)$ & 0.186
\end{tabular}

Panel 2; Bağımlı değişken ROE; *** \%1 Düzeyinde anlamlı; **\%5 Düzeyinde anlamlı; *010 Düzeyinde anlaml.

Panel 2 denkleminde bağımlı değişken ROE ile bağımsız değişkenler olan petrol (FMOLS:0.003) ve kaldıraç değişkenleri arasında istatiksel olarak anlamlı bir ilişki söz konusudur (FMOLS:0.0604). Petrol fiyatları ROE'yi aynı yönlü etkilerken, kaldıraç oranı ise ters yönde etkilemektedir. Son olarak uzun dönem ilişkinin tahmini için kurulan ve bağımlı değişkenin ROS olduğu FMOLS ve DOLS tahmin sonuçları Tablo 7'de gösterilmiştir.

Tablo 7. Panel 3 FMOLS - DOLS Tahmin Sonuçları

\begin{tabular}{|c|c|c|c|c|}
\hline Panel 3 & & & & \\
\hline Bağımsız & Uzun Dönemli & Olasılık Değeri & Uzun Dönemli & Olasılık Değeri \\
\hline Değişkenler & Katsayı & & Katsayı & \\
\hline Petrol & 346.7098 & & 380.8174 & \\
\hline & (2.734574) & 0.000 & (2.306397) & 0.021 \\
\hline Cari Oran & 5.685963 & $00-0$ & -3.802125 & קר דרת \\
\hline & (0.178945) & 0.050 & $(-0.083901)$ & 0.355 \\
\hline Likidite Oranı & & & 3.704715 & \\
\hline & ) & 0.855 & $(0.081610)$ & 0.935 \\
\hline Kaldıraç & -7.653855 & & -7.874112 & \\
\hline & $(-4.279436)$ & 0.000 & $(-3.607398)$ & 0.000 \\
\hline
\end{tabular}

Panel 3; Bağımlı değişken ROS; *** \%1 Düzeyinde anlaml1; **\%5 Düzeyinde anlamlı; *\%10 Düzeyinde anlamli. 
Panel 3 denkleminde bağımlı değişken ROS alınmış olup her iki yöntemde de (FMOLS-DOLS) petrol ve kaldıraç değişkenleri anlamlıdır. Değişkenlerin ROS'u etkileme yönleri diğer analizlerle benzerlik göstermektedir. Bu bağlamda petrol fiyatları karlılı̆̆ aynı yönlü etkilerken kaldıraç değişkeni ters yönde etkilemektedir.

\section{SONUÇ}

Çalışmada BIST Kimya endeksinde verilerine ulaşılabilen 18 firmanın 2009-2019 yılları arası verileri kullanılarak petrol fiyatları ve firma karlılığı arasındaki ilişki aranmıştır. FMOLS-DOLS analiz sonuçlarına göre petrol fiyatlarının, karlılık göstergesi olarak ele alınan ROA, ROE ve ROS değişkenlerini aynı yönde etkilemekte olduğu sonucuna ulaşılmıştır. Petrol fiyatlarında meydana gelen artış firma karlılığını arttırmaktadır. Bu ilişki literatürde firma karlılıklarına yönelik çalışmalarla benzerlik göstermektedir (Narayan ve Narayan 2014:318, Wattanatorn ve Kanchanapoon 2012:763, Dayanandan ve Donker, 2011:252). Ancak petrol ve gaz üreten firmalar dışındaki farklı sektörlerde yapılan çalışmalarda ise farklı sonuçlar elde edilmiş̧ir (Alper vd. 2016:151). Bu bağlamda çalışma literatürde ortaya konulan bulguları desteklemektedir.

Kaldıraç oranında meydana gelen artışın firma karlılığını ters yönde etkilemesi, firmaların borçluluk oranlarındaki artışın firma karlılığı ile ters yönlü ilişkisini ortaya koymaktadır. Firmaların borçluluk oranlarında meydana gelen artış firmaların karlılıklarını azaltmaktadır. Petrol fiyatlarındaki dalgalanmalar firmaların borçluluk rakamlarımda artış meydana getirebilmektedir. Ancak kaldıraç oranındaki artış firmaların varlıklarında meydana gelen azalmalardan da kaynaklanabilir. $\mathrm{Bu}$ durumda firmaların petrol fiyatlarındaki dalgalanmalardan dolayı düşük stokla çalışmaları ya da finansman ihtiyaçları için varlıklarında azalmaya gitmeleri sonucuna ulaşılabilir. Bu bağlamda petrol fiyatlarındaki değişimlerin karlılığa olan etkisinin borçluluk oranlarına veya firmaların varlık rakamlarına göre değişebileceği sonucuna ulaşılabilmektedir.

Çalışmadan elde edilen sonuçlar, kimya sektörü firmalarının petrol fiyatlarındaki değişimleri yakından takip etmeleri ve bu değişimlere göre pozisyon almaları bakımından önem arz etmektedir. Ayrıca çalışma sadece kimya sektöründe faaliyet gösteren firmalar üzerine yapılmış olup farklı sektörler için farklı sonuçlar elde edilebileceği yani sektör bazında farklı sonuçlar ortaya çıkabileceği göz önünde bulundurulmalıdır.

\section{KAYNAKLAR}

Al Mudhaf, Anwar - Goodwin, Thomas, H. (1993), "Oil Shocks and Oil Stocks: Evidence From the 1970s”, Applied Economics 25, pp.181-190.

Alper, Değer - Aydoğan, Ebru - Özkan, Nesrin - Kara, Esen (2016), "Petrol Fiyatlarının Firma Karlılığına Etkisi: Borsa İstanbul'da Bir Uygulama”, Muhasebe ve Finansman Dergisi, Ekim, ss.151-162.

Arour1, Muhammed El Hedi (2011), "Does Crude Oil Move Stock Markets in Europe? A Sector Investigation”, Economic Modelling, 28 (4), pp.1716-1725. 
Barsky, Robert - Kilıan, Lutz (2004), “Oil and the Macro-Economy since the 1970s”, Journal of Economic Perspectives, 18, pp.115-134.

Chen, Nai-Fu - Roll, Richard - ROSS, Stephen, A. (1986), "Economic Forces and the Stock Market”, Journal of Business, 59, pp.383-403.

Christopoulos, D.K. - Tsıonas, E.G. (2004), "Financial Development and Economic Growth: Evidence from Panel Unit Root and Cointegration Tests”, Journal of Development Economics, 73, pp.55-74.

Dayanandan, Ajit - Donker, Han (2011), “Oil Prices and Accounting Profits of Gas Companies”, Internetional Review of Financial Analaysis, 20, pp.252-257.

F1lıs, George - Degiannak1s, Stavros - FLOROS, Christos (2011), "Dynamic Correlation Between Stock Market and Oil Prices: The Case of Oil-Importing and Oil-Exporting Countries”, International Review of Financial Analysis, 20 (3), pp.152-164.

Hamilton, James, D. (1996), “This What Happened to the Oil Price-Macro-Economy Relationship”, Journal of Monetary Economics, 38, pp.215-220.

Hammoudeh, Shawkat - Bhar, Ramaprasad - Thompson, Mark, A. (2010), "Re-Examining the Dynamic Causal Oil- Macroeconomy Relationship", International Review of Financial Analysis, 19, pp.298-305.

Hammoudeh, Shawkat, M. - L1, Huimin (2004), "Risk-Return Relationships in Oil-Sensitive Stock Markets”, Finance Letters, 2, pp.228-248.

Hansen, Bruce, E. -Phıllıps, Peter, C.B. (1990),” Statistical Inference in Instrumental Variable Regression With I(1) Processes”, Review of Economic Studies. 57, pp.99-125.

Huang, Roger, D. - Mausulıs, Ronald, W. - Stoll, Hans R. (1996), "Energy Shocks and Financial Markets”, Journal of Futures Markets, 16, pp.1-27.

Huang, Xuan - An, Haizhong - Gao, Xiangyun - Hao, Xiaoqing - Liu, Pengpeng (2015), "Multiresolution Transmission Of The Correlation Modes Between Bivariate Time Series Based On Complex Network Theory” Phys. A: Stat. Mech. Appl., 428, pp.493506.

İşcan, Erhan (2010), “Petrol Fiyatının Hisse Senedi Piyasası Üzerindeki Etkisi”, Maliye Dergisi, Sayı. 158, ss. 607-617.

Jones, Charles, M. - Kaul, Gautam (1996), “Oil and The Stock Markets” Journal of Finance, 51 (2), pp.463-491.

Kapusuzoğlu, Ayhan (2011), "Relationships between Oil Price and Stock Market: An Empirical Analysis from Istanbul Stock Exchange (ISE)', International Journal of Economics and Finance, Vol. 3(6), pp. 99-106. 
Kilıan, Lutz - Park, Cheolbeom (2009), "The Impact of Oil Price Shocks on the US Stock Market”, International Economic Review, 50, pp.1267-1287.

Küçükaksoy, İsmail - Çifçi, İsmail - Özbek, Rabia, İnci (2015), “İhracata Dayalı Büyüme Hipotezi: Türkiye Uygulaması”, Çankırı Karatekin Üniversitesi İktisadi ve İdari Bilimler Fakültesi Dergisi, Cilt 5, Sayı 2, ss.691-720.

Malık, Farooq - Ewıng, Bradley (2009), "Volatility Transmission Between Oil Prices and Equity Sector Returns”, International Review of Financial Analysis, 18, pp.95-100.

Manımaran, P. - Panıgrahı, Prasanta, K. - Parıkh, Jitendra, K. (2009), "Multiresolution Analysis of Fluctuations in Non-Stationary Time Series Through Discrete Wavelets" Phys. A: Stat. Mech. Appl., 388 (12), pp.2306-2314.

Mohanty, Sunil, K. - Akhıgbe, Aigbe - Al-Khyal, Tawfeek A. - Bugshan, Turki (2013), “Oil and Stock Market Activity When Prices Go Up and Down: The Case of The Oil And Gas Industry”, Review of Quantitative Finance and Accounting, 41(2), pp.253-272.

Nandha, Mohan - Faff, Robert (2008), "Does Oil Move Equity Prices? A Global View”, Energy Economics, 30, pp.986-997.

Narayan, Paresh, Kumar - Narayan, Seema (2014), "Psychological Oil Price Barrier and Firm Returns”, Journal of Behavioral Finance, 15 (4), pp.318-333.

Narayan, Paresh, Kumar - Sharma, Susan, Sunila (2014), "Firm Return Volatility and Economic Gains: The Role of Oil Prices”, Economic Modelling, Vol.38 (C), pp.142151.

Pedron1, Peter (2000), “Fully-Modified OLS for Heterogeneous Cointegration Panel, In Nonstationary Panels, Panel Cointegration and Dynamic Panels”, Advances in Econ. 15, pp. 93-130.

Pradhan, Kalandi, Charan (2016), "Does Remittance Drive Economic Growth in Emerging Economies: Evidence from FMOLS and Panel VECM”, Theoretical and Applied Economics, Vol.23, No.4 (609), pp.57-74

Raza, Naveed - Shahzad, Syed - Jawad, Hussain - Tiwarı, Awiral, Kumar - Shahbaz, Muhammed (2016), “Asymmetric Impact of Gold, Oil Prices and Their Volatilities on Stock Prices of Emerging Markets”, Resources Policy, Vol.49, pp.290-301.

Sadorsky, Perry (2001), "Risk Factors in Stock Returns of Canadian Oil and Gas Companies”, Energy Economics, 23, pp.17-28.

Stock, James, H. - Watson, Mark, W. (1993), “A Simple Estimator of Co-integrating Vectors in Higher Order Integrated Systems”, Econometrica, Vol. 61, No. 4, pp.783-820.

Wattanatorn, Woraphon - Kanchanapoom, Termkiat (2012), “Oil Prices and Profitability Performance: Sector Analysis”, Procedia - Social and Behavioral Sciences 40 ( 2012 ) pp.763 - 767. 